\title{
Sugars, Organic Acids and Total Phenols in Varieties of Chestnut Fruits from Tenerife (Spain)
}

\author{
M. Hernández Suárez ${ }^{1}$, B. Rodríguez Galdón ${ }^{2}$, D. Ríos Mesa ${ }^{3}$, C. Díaz Romero ${ }^{4 *}$, \\ E. Rodríguez Rodríguez ${ }^{4}$ \\ ${ }^{1}$ Agriculture Technology National Centre "Extremadura" CTAEX, Villafranco del Guadiana, Badajoz, Spain; ${ }^{2}$ Biochemistry and \\ Molecular Biology Department, Extremadura University, Badajoz, Spain; ${ }^{3}$ Agriculture by Biodiversity Conservation Center of Tene- \\ rife, Tacoronte, Spain; ${ }^{4}$ Analytical Chemistry, Nutrition and Food Science Department, La laguna University, La laguna, Spain. \\ Email:*diaz@ull.es
}

Received May $12^{\text {th }}, 2011$; revised June $21^{\text {st }}, 2011$; accepted June $30^{\text {th }}, 2011$

\begin{abstract}
The sugar, organic and total phenol contents were determined in 21 varieties of chestnut from Tenerife (Spain). Sucrose, fructose and glucose were determined by HPLC/refraction index being the sucrose the sugar with the highest content. The organic acids were determined by HPLC/diode array, and the chestnuts had an organic acids profile characterized by the following compounds: oxalic, glutamic, tartaric, pyruvic, malic, ascorbic, citric, fumaric and cis-aconitic acids. Ascorbic, citric and malic acids were the major organic acids. There were differences in the composition of sugars, total phenols and organic acids between the chestnut varieties. The production zone only significantly affected the contents of moisture, sucrose, total phenols and fructose. The correlations between glucose-fructose, malic acid-fumaric acid, tartaric acid-oxalic acid could be emphasized. An important contribution to the intake of antioxidants is observed for the consumption of chestnuts.
\end{abstract}

Keywords: Chestnut; HPLC; Chemical Composition; Statistics

\section{Introduction}

Nuts have been part of the human diet for a long time; remains have been found in archaeological sites dating back to before 10,000 BC. Different constituents (linolenic acid, folic acid, arginine, fibre, vitamin E, potassium, copper and magnesium) positively contribute to the nutritional value of nuts [1]. These constituents occur at high levels in most nuts. In contrast to the majority of fruit nuts, chestnuts are characterized by low fat and protein contents but high carbohydrate and moisture content [2-4]. The nature and concentration of sugars and organic acids are important factors influencing the sensorial characteristics of fruit and vegetables, namely their flavour [5]. The relative amounts and the presence/absence of each compound have been considered useful in taxonomic studies [6,7] for the determination of percent fruit content in fruit derivatives (Silva et al. 2002) and also to evaluate food processing $[8,9]$. Additionally, some organic acids (ascorbic acid and phenolic acids) may have a protective role against various diseases due to their antioxidant activity [10].

Chestnut crops have been introduced into the Canary

${ }^{*}$ Corresponding author.
Islands, since colonization in the 16th century by Spanish and Portuguese settlers. In the Canary Islands, the chestnut is a secondary crop, being located in the edge of the orchards or forming wooded masses. Nowadays, thirty eight varieties of chestnuts have been identified in $\mathrm{Ca}$ nary Islands [11].

The contents of sugars, organic acids and total phenols were determined in varieties of chestnuts in order to complete the information about the chemical composition of all these varieties. In addition, we studied the influence of the production zone on the content of these parameters in chestnuts.

\section{Materials and Methods}

\subsection{Reagents and Standards}

Acetonitrile and methanol of HPLC-gradient grade, sodium dihydrogen phosphate $\left(\mathrm{NaH}_{2} \mathrm{PO}_{4}\right)$ and phosphoric acid were purchased from Merck (Darmstadt, Germany); ethanol from Scharlau (Barcelona, Spain); gallic acid from Sigma (St. Louis, MO, USA); and 2,6-dichlorophenol-indophenol from Fluka (Buchs, Switzerland). Standards of D-(+)-glucose anhydrous, D(-)-fructose, sucrose, L-glutamic, maleic, L(-)-malic, ascorbic and 
oxalic acids were supplied by Fluka (Buchs, Switzerland); cis-aconitic, trans-aconitic, fumaric, (-)-quinic, L-(+)tartaric acids and sodium pyruvate came from Sigma (St. Louis, MO, USA); citric, shikimic and succinic acids from Aldrich (Milwaukee, WI, USA). Stock solutions for sugar analysis $(1 \mathrm{~g} / \mathrm{L})$ and organic analysis $(5 \mathrm{~g} / \mathrm{L})(\mathrm{ex}-$ cept for ascorbic acid that was prepared in metaphosforic acid $0.375 \mathrm{M}$ ) were prepared in ultrapure water (Millipore, Bedford, MA) and stored in darkness at $5^{\circ} \mathrm{C}$. Deionized water was purified with a Milli-Q water system (Millipore, Bedford, MA).

\subsection{Sampling and Sample Preparation}

A total of 40 samples of chestnuts belonging to 21 different varieties were collected and authenticated by technicians from the Excmo. Cabildo Insular de Tenerife (Insular Government). The main characteristics of the analyzed chestnut samples are described in Table 1. The chestnut samples were collected from two production zones of the island of Tenerife (Spain), namely: La Orotava, La Matanza de Acentejo, La Victoria de Acentejo and El Sauzal in the north of the island; and Arafo in the south of the island. The age of the chestnut trees ranged between 40 and 200 years. The relief of Tenerife is a steep and mountainous, dominated by the presence of the Mount Teide $(3718 \mathrm{~m})$, which separates the island into two slopes (South and North side) that differ significantly in terms of their climatic conditions. The southern zone is characterized by windier and drier meteorological conditions compared to the northern zone. In the northern zone, the average temperature between 1980 and 2000 was $16.5^{\circ} \mathrm{C}\left(12.9^{\circ} \mathrm{C}-20.0^{\circ} \mathrm{C}\right)$ and in the southern zone was $21.3^{\circ} \mathrm{C}\left(17.9^{\circ} \mathrm{C}-24.7^{\circ} \mathrm{C}\right)$. Also, the average rainfall per year were 557 and $116 \mathrm{~mm}$ for the northern and southern zone, respectively.

After harvesting, the chestnuts (approximately 30 - 50 units) were brought to the laboratory and were prepared immediately. The shell (pericarp) and skin (endocarp) were removed, and the chestnuts were immediately homogenized with a mincer (Solac, Vitoria, Spain) during a $3 \mathrm{~min}$, to obtain a puree. Several sub-samples were taken to measure moisture. For ascorbic acid, approximately 3 $\mathrm{g}$ of this homogenized was introduced into an erlenmeyer containing $10 \mathrm{~mL}$ of metaphosphoric acid $0.375 \mathrm{M}$, and then they were frozen at $\mathrm{T}=-80^{\circ} \mathrm{C}$. The rest of homogenized was stored in a polyethylene tube at $-80^{\circ} \mathrm{C}$ until analysis.

\subsection{Analytical Determinations}

Moisture was immediately determined in the homogeneized chestnuts by the oven drying method [12]. The total phenols content in the chestnut samples were de- termined at $750 \mathrm{~nm}$ using a Hewlett Packard 8453 (Waldbronn, Germany) spectrophotometer after the colourimetric reaction with the Folin-Ciocalteu reagent (Sigma, St. Louis, MO) by following the method proposed by Kujala et al. [13]. Gallic acid standard (Sigma; St. Louis, MO) solutions were used for the external standard calibration curve. The ascorbic acid was determined by the 2,6-dichlorophenol-indophenol titration procedure [12]. All these analysis were carried out in triplicate.

\subsection{Sugars Analysis}

The determination of sugars was performed by HPLC according to the method described by Rodríguez Galdón et al. [14]. About $1 \mathrm{~g}$ of the frozen homogenized chestnut was weighed directly in polypropylene tubes and mixed with $2 \mathrm{~mL}$ of $4: 1$ ethanol:water. Afterwards, the tubes were put into an ultrasound bath for 5 min and centrifuged for $5 \mathrm{~min}$ at $1090 \cdot \mathrm{g}$. The supernatant was carefully recovered to prevent contamination. Then, another $2 \mathrm{~mL}$ of 4:1 ethanol:water was added to the pellet and placed in an ultrasound bath and centrifuged as above. The two supernatants were recovered in the same tube. This liquid phase was concentrated with a nitrogen stream until elimination of all the ethanol, and the residue was adjusted to $5 \mathrm{~mL}$ with ultra-pure water (Milli-Q water system) and stored at $\mathrm{T}=-80^{\circ} \mathrm{C}$ in the freezer. A milliliter of the dissolution was passed through a $0.45 \mu \mathrm{m}$ filter GHP (Waters, Millford, MA, USA) prior to HPLC analysis.

The sugars were determined using an HPLC method with differential refractive index (DRI) detector. The Waters (Milford, MA, USA) apparatus comprised of a pump (600 E Multisolvent Delevery System), an autosampler (700 Wisp Model) and a DRI detector (Waters model 2414). The separation was performed by using a Waters Carbohydrate Analysis column $(3.9 \times 300 \mathrm{~mm})$ with a particle size diameter of $10 \mu \mathrm{m}$, equipped with a Waters Carbohydrate Carbo ${ }^{\mathrm{TM}} 4 \mu \mathrm{m}$ guard column. The column was kept at $25^{\circ} \mathrm{C}$ throughout the experiments. The HPLC pumps, autosampler, column oven and DRI detector were monitored and controlled using the Millennium ${ }^{32}$ system.

The mobile phase was composed of $4: 1$ acetonitrile:water. The injection volumes of the samples were 25 $\mu \mathrm{L}$ for both standards and sample extracts, with a flow rate of $2 \mathrm{~mL} \cdot \mathrm{min}^{-1}$. The HPLC sample peaks were identified by comparing the retention times obtained from standards. The chestnut samples were also spiked with standards in order to verify the identity of the chromatographic peaks. Duplicate injections were performed and average peak areas were used for the quantification. 
Table 1. Description of chestnut varieties and zones of production.

\begin{tabular}{|c|c|c|c|c|}
\hline Variety & Municipality & Number of samples & Production zone & Weight (g/unit) \\
\hline Arafera & La Orotava & 1 & North & $12.6 \pm 2.1$ \\
\hline \multirow{2}{*}{ Castagrande } & El Sauzal; & 2 & North & $7.5 \pm 3.1$ \\
\hline & La Matanza de Acentejo & 1 & North & $10.2 \pm 0.1$ \\
\hline Corujera & La Orotava & 1 & North & $4.2 \pm 0.7$ \\
\hline Culochico & La Victoria de Acentejo & 2 & North & $8.1 \pm 0.1$ \\
\hline De Pata & El Sauzal & 1 & North & $5.2 \pm 1.0$ \\
\hline \multirow{2}{*}{ De Sala } & El Sauzal; & 2 & North & \multirow{2}{*}{$10.8 \pm 2.6$} \\
\hline & Arafo & 1 & South & \\
\hline Del Haya & La Victoria de Acentejo & 2 & North & $8.1 \pm 0.5$ \\
\hline Donosa & La Orotava & 1 & North & $10.6 \pm 2.1$ \\
\hline Grande & La Victoria de Acentejo & 1 & North & $7.7 \pm 0.9$ \\
\hline \multirow{2}{*}{ Mansa } & La Matanza de Acentejo; & 1 & North & \multirow{2}{*}{$9.2 \pm 2.5$} \\
\hline & Arafo & 2 & South & \\
\hline Matancera & La Victoria de Acentejo & 1 & North & $5.3 \pm 1.1$ \\
\hline \multirow[t]{3}{*}{ Mollar } & El Rosario & 1 & North & $6.4 \pm 1.8$ \\
\hline & El Sauzal; & 1 & North & \multirow{5}{*}{$9.2 \pm 3.1$} \\
\hline & La Matanza de Acentejo; & 1 & North & \\
\hline \multirow[t]{3}{*}{ Mulata } & La Victoria de Acentejo; & 1 & North & \\
\hline & Arafo; & 2 & South & \\
\hline & La Orotava & 2 & North & \\
\hline Negra & La Victoria de Acentejo & 2 & North & $8.4 \pm 0.4$ \\
\hline Pico Claro & La Orotava & 3 & North & $5.8 \pm 2.9$ \\
\hline Picuda & La Victoria de Acentejo & 1 & North & $7.7 \pm 1.6$ \\
\hline Piñera & La Orotava & 1 & North & $8.5 \pm 2.1$ \\
\hline \multirow[t]{2}{*}{ Polegre } & La Victoria de Acentejo & 1 & North & \multirow[t]{2}{*}{$9.8 \pm 1.4$} \\
\hline & El Sauzal; & 1 & North & \\
\hline \multirow[t]{2}{*}{ Redonda } & La Matanza de Acentejo; & 1 & North & \multirow[t]{2}{*}{$5.9 \pm 1.4$} \\
\hline & La Victoria de Acentejo & 1 & North & \\
\hline Siete Pernadas & La Orotava & 1 & North & $9.6 \pm 2.3$ \\
\hline Temprana & La Orotava & 1 & North & $2.5 \pm 0.9$ \\
\hline Overall & & 40 & & $8.1 \pm 2.7$ \\
\hline
\end{tabular}




\subsection{Organic Acids Analysis}

The organic acids were determined using a HPLC method with diode array detector described by Hernández Suárez et al. [15]. $2 \mathrm{~mL}$ of the previously obtained solution in the "Sugar analysis" section were passed through a 0.45 $\mu \mathrm{m}$ filter GHP (Waters, Millford, MA, USA) and through a Sep-Pak Accell Plus QMA cartridge (Waters, Millford, MA, USA), which was previously preconditioned with $3 \mathrm{~mL}$ of ultrapure water (Milli-Q water system). The compounds were eluted with $2 \mathrm{~mL}$ of sodium dihydrogen phosphate $20 \mathrm{mM}$ to $\mathrm{pH}=1$.

The analytical HPLC system was a Waters 2690 high-performance liquid chromatograph equipped with a Waters 996 photodiode array detector (Water, Milford, MA, USA). The separation was performed using a Waters Atlantis dC18 steel column $(150 \times 4.6 \mathrm{~mm}$ i.d. $)$ with a particle diameter of $3 \mu \mathrm{m}$ equipped with a Waters Atlantis $(20 \times 4.6 \mathrm{~mm}) \mathrm{dC} 18$ guard column. The temperature of the column was set at $\mathrm{T}=25^{\circ} \mathrm{C}$ during all the experiments. The HPLC pumps, autosampler, column oven, and diode-array system were monitored and controlled using the Millennium ${ }^{32}$ system. A wavelength of $210 \mathrm{~nm}$ was used for the detection of the organic acids.

The mobile phase was composed of sodium dihydrogen phosphate $20 \mathrm{mmol} / \mathrm{L}$ to $\mathrm{pH}=2.7$. The injection volumes were $10 \mu \mathrm{L}$ for both standards and sample extracts, and a flow rate of $0.7 \mathrm{~mL} / \mathrm{min}$ was used. Duplicate injections were performed and average peak areas were used for the quantification. The HPLC peaks were identified by comparing the retention times and spectral data obtained from standards.

\subsection{Statistics}

Statistical analyses were performed by means of the SPSS version 17.0 (SPSS Inc., Chicago, USA). One-Way ANOVA (Duncan's multiple range) was realized, assuming there were significant differences among them when the statistical comparison gave $\mathrm{p}<0.05$. Correlation analysis was carried out to know relationships between variables.

\section{Results and Discussion}

In a previously published paper [16], we studied the influence of peeling methods and storage conditions of the chestnuts on the some physicochemical parameters including ascorbic acid and phenolic compounds. Slight losses of moisture, ascorbic acid and phenolic compounds were observed using the manual peeling comparing with the microwave peeling. Also, a decrease of moisture, ascorbic acid and phenolic compounds in chestnuts stored at refrigeration during 60 days, and after 3 days at refrigeration of samples previously homoge- nized. Also, Barbosa et al. [17] studied changes of many compounds in different steps (fresh, after storage for 2 months at $0^{\circ} \mathrm{C}$, after industrial steam peeling at Sortegel, and after freezing with liquid air and $-20^{\circ} \mathrm{C}$ at Sortegel) of the processing. They found significant differences in the contents of phenolic compounds.

Table 2 shows the results relative to moisture, sugars and total phenols of the chestnut varieties analyzed. Moisture content ranged between 496 and $620 \mathrm{~g} / \mathrm{kg}$ for the varieties Culochico and De pata respectively. Only the De pata variety had moisture content above the range $490-600 \mathrm{~g} / \mathrm{kg}$, which is considered adequate for conservation of chestnuts. Our values are near the data reported by other investigators [18-22].

Sucrose is the main sugar present in the chestnuts, and it is one of the most important parameters for the assessment of the commercial quality of chestnuts [20]. It represents an intermediate availability form of carbohydrate between starch and the simple monosaccharides such as glucose and fructose [22]. The mean concentration of sucrose was $73.9 \pm 20.1 \mathrm{~g} / \mathrm{kg}$ of dry weight (d.w.) finding important variation between the varieties of chestnuts analyzed, 31.1 and $99.4 \mathrm{~g} / \mathrm{kg}$ in Picuda and Mollar varieties respectively. Our results were lower than other data found in the literature $[3,20,22-25]$. This could be explained because our chestnut samples were immediately processed after harvesting. De la Montaña Míguelez et al. [22] reported values around 65.5 and $195 \mathrm{~g} / \mathrm{kg}$ d.w., although most of chestnuts were in the range 80 $150 \mathrm{~g} / \mathrm{kg}$. In a recent and wide study to assess the quality characteristics of fifteen chestnut varieties from five Mediterranean countries found sucrose contents between 85.3 and $215 \mathrm{~g} / \mathrm{kg}$ d.w., which were above our data [20]. Only, Senter et al. [4] found similar values of sucrose in European chestnuts to our data, $92.5 \mathrm{~g} / \mathrm{kg}$ d.w.

As expected glucose and fructose were hardly detected. Senter et al. [4] reported that fructose and glucose were present in trace amounts $(<0.10 \mathrm{mg} / \mathrm{kg}$ d.w.). However, our data were lower than those reported by other authors [22-25]. De la Montaña Míguelez et al. [22] found glucose and fructose concentrations between 0.0 and 3.1 $\mathrm{g} / \mathrm{kg}$ d.w. for both monosaccharides respectively. Künsch et al. [2,3] found higher concentrations of fructose (3.7 $6.9 \mathrm{~g} / \mathrm{kg}$ d.w. $)$, and similar of glucose $(1.0-1.2 \mathrm{~g} / \mathrm{kg}$ d.w.), than the corresponding data reported here. The ratio glucose/fructose was near 1 which suggests they were the result of sucrose hydrolysis [22]. Borges et al. [19] determined reductor sugars using the AOAC method, and they found values between 17.7 and $36.7 \mathrm{~g} / \mathrm{kg}$ d.w.

Total phenol contents showed a mean value for all the samples of $2.84 \pm 0.67 \mathrm{~g}$ gallic acid $\mathrm{kg}^{-1}$ d.w. $(1.24 \pm$ $0.29 \mathrm{~g}$ gallic acid $\mathrm{kg}^{-1}$ fresh weight (f.w.)). The contents of total phenols were compared with other vegetables and fruits cultivated in Tenerife. One can deduce that the 
Table 2. Mean concentrations (g/kg d.w.) of dry matter, sugars and total phenols in the chestnut varieties analyzed.

\begin{tabular}{|c|c|c|c|c|c|}
\hline Variety & Dry matter & Sucrose & Fructose & Glucose & Total phenols \\
\hline Arafera & 467 & 84.5 & 0.64 & 1.07 & 2.63 \\
\hline Castagrande & 421 & 41.1 & 0.56 & 0.49 & 2.68 \\
\hline Corujera & 417 & 51.8 & 0.96 & 0.96 & 3.27 \\
\hline Culochico & 504 & 82.3 & 0.60 & 0.70 & 2.79 \\
\hline De pata & 380 & 84.7 & 2.40 & 1.84 & 2.13 \\
\hline De sala & 419 & 67.5 & 1.27 & 1.11 & 2.60 \\
\hline Del Haya & 426 & 77.0 & 1.06 & 0.83 & 3.11 \\
\hline Donosa & 439 & 89.2 & 0.68 & 0.68 & 2.53 \\
\hline Grande & 405 & 54.4 & 1.48 & 0.99 & 3.10 \\
\hline Mansa & 453 & 68.4 & 1.53 & 1.09 & 2.33 \\
\hline Matancera & 406 & 63.5 & 1.72 & 1.90 & 2.27 \\
\hline Mollar & 469 & 99.4 & 0.85 & 1.07 & 2.64 \\
\hline Mulata & 444 & 82.7 & 1.37 & 1.04 & 3.13 \\
\hline Negra & 451 & 91.8 & 1.12 & 1.11 & 2.85 \\
\hline Pico claro & 473 & 84.9 & 0.64 & 0.85 & 3.57 \\
\hline Picuda & 405 & 31.1 & 0.25 & 0.25 & 3.10 \\
\hline Piñera & 426 & 67.8 & 1.17 & 0.70 & 2.91 \\
\hline Polegre & 489 & 84.6 & 0.61 & 1.02 & 1.96 \\
\hline Redonda & 417 & 73.5 & 0.81 & 0.88 & 2.27 \\
\hline Siete pernadas & 448 & 75.6 & 0.89 & 0.89 & 2.95 \\
\hline Temprana & 426 & 85.6 & 1.17 & 0.94 & 4.31 \\
\hline Overall & $440 \pm 34$ & $73.9 \pm 20.1$ & $1.06 \pm 0.54$ & $0.95 \pm 0.38$ & $2.84 \pm 0.67$ \\
\hline
\end{tabular}

d.w.: dry weight.

contents of phenolic compounds in chestnut can only be compared with those reported for the specie $O$. dillenii of prickly pears [26], whose fruits have an intense violet colour. Therefore, the chestnuts are an important source of these antioxidant compounds. There are not recommended dietary intakes of phenolic compounds. However, the American Cancer Society [27] has established 100 mg per day of flavonoids as an adequate amount for the prevention of cancer and degenerative illness. The consumption of one serving of chestnut represents an intake of $\approx 124 \mathrm{mg}$ of phenolic compounds, including the flavonoids. The mean contents in the varieties analyzed ranged between 1.96 and $4.31 \mathrm{~g} / \mathrm{kg}$ d.w. for the De pata and Temprana varieties, respectively. Data of total phenols obtained by us agreed with those indicated by Xu et al. [28] previous transformation of their values, expressed in $\mathrm{mg}$ chatequin $/ 100 \mathrm{~g}$ d.w., to the units that our results are expressed. Besides, our data were slightly higher than those results $(1.27-2.35 \mathrm{~g} / \mathrm{kg}$ d.w.) reported by Vekiari et al. [29] which found the highest values in Spanish chestnuts followed by Greek nuts. In other papers $[17,25,30,31]$ the data reported were sensitively lower than the data presented in this paper. This could be explained because those investigators determined only polyphenols using a different method. On the other hand, Barreira et al. [32] determined and compared antioxidant activities in different extracts from chestnut such as: flower, leaf, skin and fruit. They found values of $3.73 \mathrm{~g}$ gallic acid $\mathrm{kg}^{-1}$ in the extract of chestnut fruit, and indicated that the polyphenol contents arranged according to the following sequence: outer skins $>$ inner skins $>$ flowers $>$ leaves $>>>$ fruit.

Figure 1 shows a chromatogram corresponding to an eight-component mixture of standards (a) and a chestnut sample (b). One can observe the good resolution and separation of the identified organic acids in a real sample 


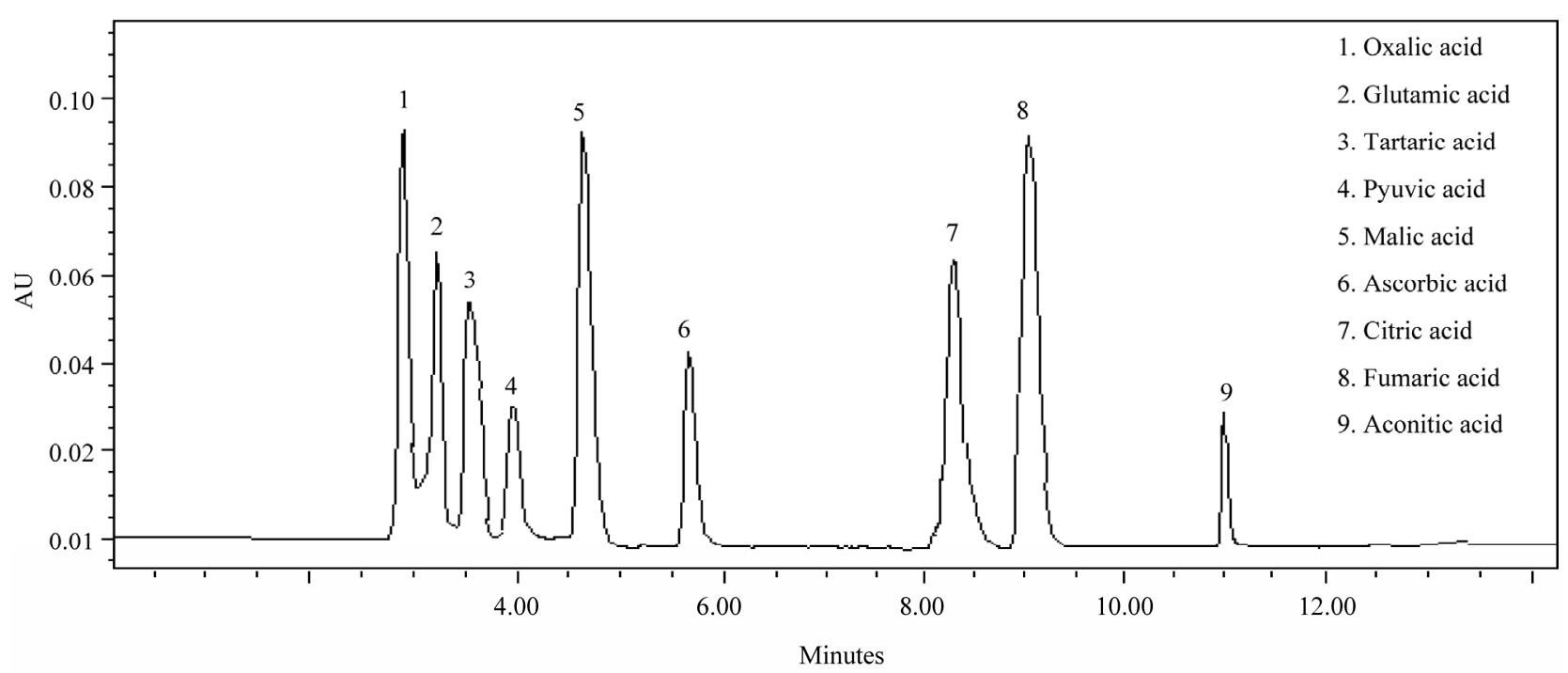

(a)

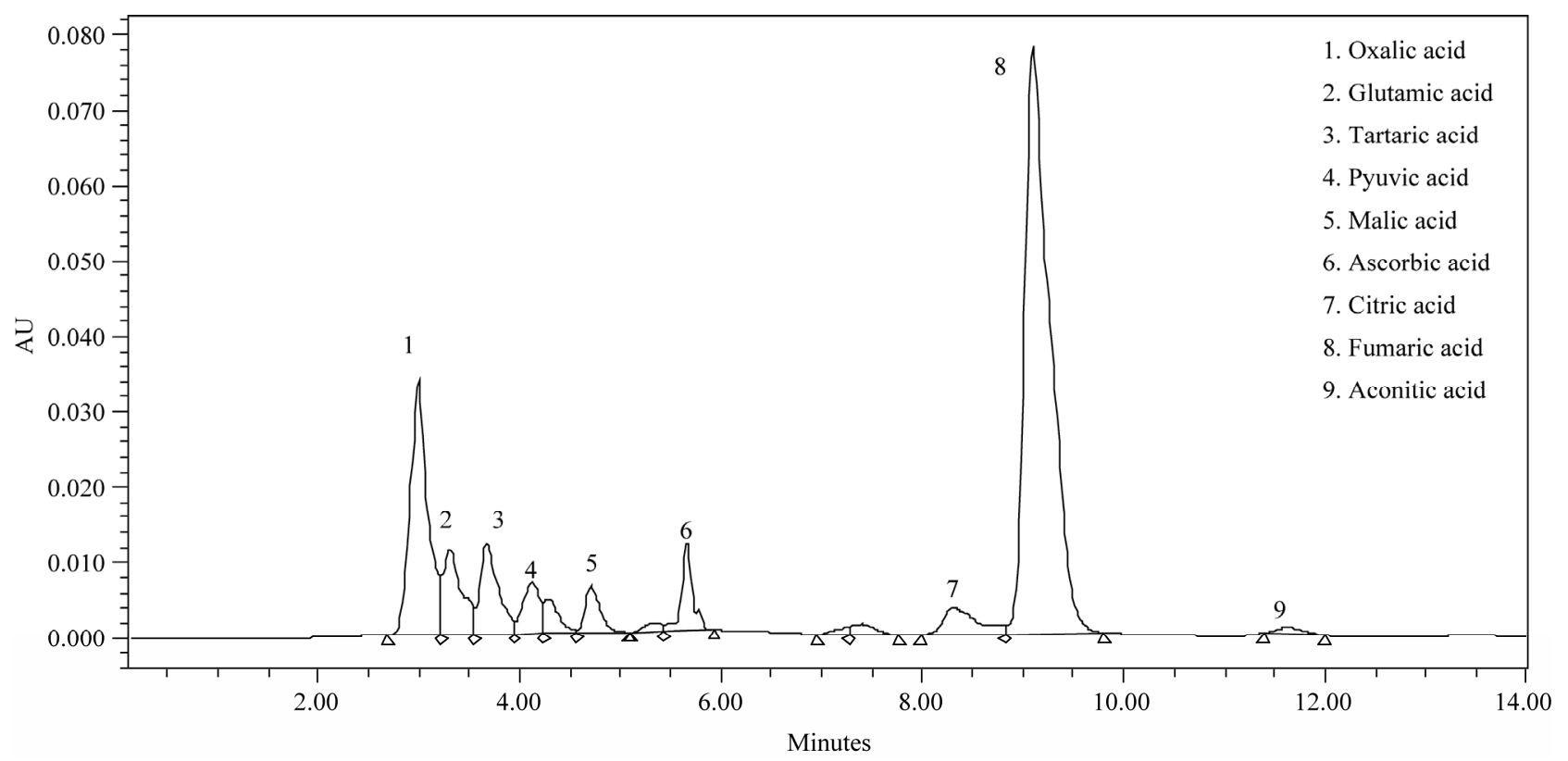

(b)

Figure 1. Chromatograms of a nine organic acids standards (a) and a chestnut sample (b).

of chestnut using the isocratic elution described in experimental section. Besides, other organic acids such as ascorbic, shikimic, cis-aconitic and quinic acids were used to try to identify the chromatographic peaks in the real samples. The identification of the observed peaks was carried out checking the retention time and the absorption spectra of the each organic acid of both real onion samples and the standards in the range between 190 $\mathrm{nm}$ and $400 \mathrm{~nm}$. Nine organic acids were separated and identified in most of chestnut samples analyzed: oxalic, glutamic, tartaric, pyruvic, malic, ascorbic, citric, fumaric and cis-aconitic acids. We were not able to identify quinic acid which contrasted with the results reported by
Ribeiro et al. [33]. However, these authors did not detect glutamic, pyruvic and tartaric acids which was found in this paper. These authors quantified oxalic and cis-aconitic acids together because both organic acids were overlapped in the chromatogram. Using the experimental conditions described in the experimental section, the chromatographic peaks of both organic acids were well separated (Figure 1). Besides, the analysis time for the determination of these organic acids was approximately $14 \mathrm{~min}$, which was lower than the time indicated $(\approx 70$ min) in this paper Ribeiro et al. [33].

Besides, the trans-aconitic acid, detected (retention time $=14 \mathrm{~min}$ ) to trace level in the most of the samples 
analyzed, is considered to be an artefact, resulting from the rapid isomerization of the cis-aconitic acid [34], a phenomenon also observed with the standards solution. The ascorbic acid was detected in most of the samples but the values obtained were very low when compared with those values obtained using titration with 2,6-dichlorophenol-indophenol [16]. The treatment of the extraction of the organic acids from the matrix of chestnut implies losses of this unstable acid. The high instability of ascorbate in aqueous solution was reported earlier $[35,36]$ and metaphosphoric acid is generally used as a stabilizing agent. Some authors [37] have also observed residual and progressive on-column decomposition, probably due to the interaction between ascorbate and stationary phase. Therefore, the ascorbic acid determined by
HPLC was not included in this paper. However, we have included the result of ascorbic acid obtained by the titration method described in the previous paper to calculate the sum of all the organic acids.

Table 3 shows the results of the organic acids in both overall terms and in terms of individual groupings of the chestnut samples according to the variety. All the organic acids (except cis-aconitic acid) were detected in all the chestnut samples. Considering the mean concentration in the quantified chestnut samples, ascorbic, citric and malic acids were the major organic acid which agrees with that reported in other papers $[29,33]$. The sum of these three organic acids represents a $56.9 \%$ of the total sum of organic acids. The mean value of ascorbic acid for all the chestnut samples was $728 \pm 178 \mathrm{~m} \mathrm{~g} / \mathrm{kg}$ d.w., ranging

Table 3. Mean concentrations of organic acids (g/kg d.w.) in several chestnut varieties.

\begin{tabular}{|c|c|c|c|c|c|c|c|c|c|}
\hline Variety & $\begin{array}{l}\text { Ascorbic } \\
\text { acid }\end{array}$ & $\begin{array}{c}\text { Citric } \\
\text { acid }\end{array}$ & $\begin{array}{c}\text { Malic } \\
\text { acid }\end{array}$ & $\begin{array}{l}\text { Oxalic } \\
\text { acid }\end{array}$ & $\begin{array}{l}\text { Glutamic } \\
\text { acid }\end{array}$ & $\begin{array}{c}\text { Tartaric } \\
\text { acid }\end{array}$ & $\begin{array}{c}\text { Fumaric } \\
\text { acid }\end{array}$ & $\begin{array}{l}\text { cis-aconitic } \\
\text { acid }\end{array}$ & $\begin{array}{l}\text { Pyruvic } \\
\text { acid }\end{array}$ \\
\hline Arafera & 769 & 570 & 517 & 293 & 507 & 246 & 182 & 59.7 & 70.2 \\
\hline Castagrande & 597 & 1135 & 640 & 762 & 521 & 367 & 227 & 90.0 & 22.5 \\
\hline Corujera & 674 & 727 & 447 & 1667 & 192 & 494 & 199 & 32.4 & 35.2 \\
\hline Culochico & 775 & 489 & 418 & 391 & 555 & 142 & 155 & 83.7 & 44.0 \\
\hline De pata & 718 & 572 & 1096 & 1205 & 223 & 850 & 321 & 187 & 13.4 \\
\hline De sala & 714 & 1055 & 665 & 652 & 364 & 160 & 160 & 128 & 32.9 \\
\hline Del Haya & 888 & 591 & 752 & 581 & 483 & 179 & 235 & 83.9 & 31.8 \\
\hline Donosa & 692 & 1009 & 731 & 339 & 722 & 153 & 248 & 82.6 & 37.3 \\
\hline Grande & 298 & 383 & 388 & 470 & 685 & 84.5 & 55.6 & 86.5 & 9.6 \\
\hline Mansa & 771 & 722 & 569 & 496 & 607 & 171 & 200 & 85.3 & 27.3 \\
\hline Matancera & 842 & 695 & 731 & 515 & 497 & 203 & 277 & 51.5 & 28.8 \\
\hline Mollar & 767 & 693 & 377 & 450 & 583 & 321 & 117 & 56.1 & 33.9 \\
\hline Mulata & 836 & 748 & 606 & 454 & 490 & 197 & 200 & 82.5 & 39.9 \\
\hline Negra & 812 & 405 & 857 & 194 & 502 & 115 & 277 & ND & 66.4 \\
\hline Pico claro & 654 & 672 & 532 & 564 & 348 & 281 & 194 & 106 & 51.9 \\
\hline Picuda & 778 & 261 & 326 & 218 & 561 & 92.2 & 33.6 & 69.7 & 11.6 \\
\hline Piñera & 753 & 1075 & 467 & 451 & 323 & 202 & 133 & 48.6 & 13.4 \\
\hline Polegre & 687 & 283 & 311 & 258 & 632 & 117 & 117 & 94.4 & 56.4 \\
\hline Redonda & 607 & 596 & 433 & 307 & 443 & 137 & 156 & 128 & 56.5 \\
\hline Siete pernadas & 833 & 830 & 599 & 72.7 & 332 & 134 & 211 & ND & 36.4 \\
\hline Temprana & 500 & 969 & 596 & 1235 & 195 & 433 & 183 & 230 & 30.0 \\
\hline Overall & $728 \pm 178$ & $720 \pm 263$ & $585 \pm 227$ & $525 \pm 361$ & $470 \pm 179$ & $223 \pm 156$ & $190 \pm 76$ & $96.2 \pm 53.5$ & $37.8 \pm 21.3$ \\
\hline
\end{tabular}

$\mathrm{ND}=$ non detected. 
between $888 \mathrm{mg} / \mathrm{kg}$ and $298 \mathrm{mg} / \mathrm{kg}$, for the Del Haya and Grande varieties, respectively. The latter value was relatively low comparing with the rest of varieties, which had values of ascorbic acid above $500 \mathrm{mg} / \mathrm{kg}$ d.w. Vekiari et al. [20] reported a mean value for ascorbic acid of $385 \mathrm{mg} / \mathrm{kg}$ d.w., which is lower than our values of ascorbic acid. Neri et al. [25] found levels of ascorbic acid in several Italian chestnut varieties ranging between 280 and $1280 \mathrm{mg} / \mathrm{kg} \mathrm{d.w.,} \mathrm{and} \mathrm{our} \mathrm{data} \mathrm{fell} \mathrm{well} \mathrm{within}$ this interval. The results of ascorbic acid confirm that the chestnuts are a good source of vitamin $\mathrm{C}$ because of the consumption of a service of $100 \mathrm{~g}$ of chestnut contributes approximately in a $53 \%$ of the recommended dietary allowances of vitamin C $(60 \mathrm{mg})$ in the adult [38]. Our results of citric and malic acids were lower than the data reported by Vekiari et al. [29] for chestnuts from Mediterranean countries, and higher than those data published for Ribeiro et al. [33] in two Portuguese varieties. Probably the treatment of samples for the extraction of the organic acids, prior the chromatographic injection, is a determinant factor influencing the contents of these organic acids. The mean concentrations of citric acid in the varieties studied ranged between 261 and $1135 \mathrm{mg} / \mathrm{kg}$ d.w. for the Picuda and Castagrande varieties, respectively. The variation was relatively high with a coefficient of variation (CV) of $37 \%$ for overall of samples. The malic acid showed a mean concentration of $585 \pm 227 \mathrm{mg} / \mathrm{kg}$ d.w. presenting a $\mathrm{CV}=39.0 \%$ similar to the citric acid. Malic acid values are much higher than those data reported by Senter et al. [4] and by Ribeiro et al. [33]. However, our concentrations of malic acid were lower than those concentrations indicated by Neri et al. [25]. These considerable differences could be attributed to differences in the applied methods. After these three major organic acids, the oxalic and glutamic acids showed the highest mean concentrations. Same of citric and malic acids, the mean concentration of oxalic acid was higher than the mean value reported by Ribeiro et al. [33]. The concentration of oxalic acid varied between 73 and $1667 \mathrm{mg} / \mathrm{kg}$ d.w. for the Siete pernadas and Corujera varieties. A high relative variation was found in oxalic acid $(\mathrm{CV}=69 \%)$. If the oxalic acid/calcium ratio $[16,39]$ is calculated for all the varieties, one can deduce that our values were substantially higher than 2.25 that is a threshold value above which the food is considered descalcyfing [40]. The rest of organic acids had lower concentrations and was arranged according to the following sequence: Tartaric acid $>$ fumaric acid $>$ cis-aconitic acid $>$ pyruvic acid. These four acids had a high variation (CV $>50 \%)$, except the fumaric acid.

The results of the parameters analyzed were studied in De sala, Manso and Mulato varieties and in the three varieties together, grouping the chestnut samples according to zone of production (Table 4). No significant

Table 4. Mean sugars, total phenols and organic acids content (g/kg d.w.) in the three chestnut varieties analyzed in both production zones and for these three varieties together.

\begin{tabular}{|c|c|c|c|c|c|c|c|c|}
\hline & \multicolumn{2}{|c|}{ De sala } & \multicolumn{2}{|c|}{ Mulato } & \multicolumn{2}{|c|}{ Manso } & \multicolumn{2}{|c|}{ Total } \\
\hline & North & South & North & South & North & South & North & South \\
\hline Dry matter & 412 & 433 & 430 & 479 & 402 & 478 & $436 \pm 34$ & $469 \pm 21.7$ \\
\hline Sucrose & 80.4 & 41.6 & 93.0 & 56.8 & 91.3 & 56.9 & $76.9 \pm 19.2$ & $53.8 \pm 14.8$ \\
\hline Glucose & 1.05 & 1.11 & 0.94 & 1.17 & 1.04 & 1.20 & $0.93 \pm 0.36$ & $1.17 \pm 0.52$ \\
\hline Fructose & 1.37 & 1.08 & 1.19 & 1.74 & 1.19 & 1.71 & $0.99 \pm 0.48$ & $1.60 \pm 0.73$ \\
\hline Total phenols & 2570 & 2650 & 3548 & 2086 & 3033 & 1975 & $2936 \pm 642$ & $2155 \pm 378$ \\
\hline Ascorbic acid & 757 & 627 & 817 & 883 & 644 & 834 & $716 \pm 183$ & $812 \pm 109$ \\
\hline Citric acid & 1179 & 807 & 796 & 627 & 509 & 828 & $717 \pm 274$ & $743 \pm 194$ \\
\hline Malic acid & 814 & 365 & 689 & 400 & 760 & 473 & $608 \pm 228$ & $422 \pm 145$ \\
\hline Oxalic acid & 825 & 307 & 555 & 199 & 746 & 371 & $559 \pm 372$ & $289 \pm 114$ \\
\hline Glutamic acid & 330 & 433 & 485 & 503 & 328 & 746 & $454 \pm 167$ & $587 \pm 233$ \\
\hline Tartaric acid & 198 & 83.1 & 246 & 74.3 & 203 & 154 & $232 \pm 135$ & $108 \pm 52.1$ \\
\hline Fumaric acid & 199 & 82.9 & 225 & 137 & 243 & 179 & $197 \pm 76$ & $143 \pm 54.8$ \\
\hline cis-aconitic acid & 123 & 137 & 78.0 & 105 & 76.4 & 94.3 & $94.7 \pm 39.5$ & $112 \pm 22.4$ \\
\hline Piruvic acid & 42.0 & 14.6 & 44.7 & 27.7 & 41.5 & 20.1 & $43.6 \pm 20.2$ & $22.0 \pm 7.64$ \\
\hline
\end{tabular}


differences $(p<0.05)$ were found in the mean values of all the parameters considered, except for oxalic acid, sucrose and total phenols in De sala, Mulato and Manso cultivars respectively. The mean values of oxalic acid, sucrose and total phenols in the chestnut samples harvested in the north were higher $(\mathrm{p}<0.05)$ than the mean values found in the south of the island for De sala, $\mathrm{Mu}-$ lato and Manso varieties respectively. The chestnut samples harvested in the Northern zone had a higher mean moisture, sucrose and total phenols contents, and lower mean fructose content, than the chestnut from the Southern zone. Many factors associated to the production zone such as climate, soil, ripening stage or cultivation practices could be influencing the chemical composition of chestnuts, which could explain the differences found between both zones of cultivation.

Many significant correlations were observed between the variables analyzed. The moisture showed correlations $(\mathrm{p}<0.01)$ with oxalic acid $(\mathrm{r}=0.492)$, tartaric acid $(\mathrm{r}=$ $0.420)$ and malic acid $(r=0.520)$. Total phenols exhibited a moderate correlation with oxalic acid $(\mathrm{r}=0.416)$, and weak correlations with glutamic acid $(\mathrm{r}=-0.379)$ and tartaric acid $(\mathrm{r}=0.330)$. The correlation glucose $v s$ fructose can be emphasized for the high correlation coefficient $(r=0.837)$, which has been observed in other fruits and suggests a common origin for both sugars, probably from the sucrose. Sucrose is the sugar used for mobilization of carbon in vascular plants. It can be synthesized from trioses phosphate produced in the photosynthesis or from starch of the chloroplasts during the night [41]. Besides, the fructose presented significant correlations with the malic acid $(r=0.509)$, fumaric acid $(\mathrm{r}=0.352)$, and inverse with pyruvic acid $(\mathrm{r}=-0.335)$; the sucrose with the malic acid $(\mathrm{r}=0.345)$, fumaric acid $(\mathrm{r}=0.318)$ and pyruvic acid $(\mathrm{r}=0.454)$; and the glucose with malic acid $(r=0.462)$ and fumaric acid $(r=0.441)$. The correlation between malic and fumaric acids $(\mathrm{r}=$ 0.852) can be emphasized within the correlations between organic acids. Besides which the tartaric acid had correlations with citric acid $(\mathrm{r}=0.354)$, oxalic acid $(\mathrm{r}=$ $0.780)$, malic acid $(\mathrm{r}=0.486)$ and fumaric acid $(\mathrm{r}=$ $0.542)$, and inversely with glutamic acid $(\mathrm{r}=-0.411)$. The oxalic acid was weakly correlated with citric acid $(\mathrm{r}$ $=0.368)$, malic acid $(\mathrm{r}=0.346)$, cis-aconitic acid $(\mathrm{r}=$ $0.382)$, and inversely with glutamic acid $(\mathrm{r}=-0.493)$. All the correlations found reflect that these sugars and organic acids are part of common and complex metabolic routes.

\section{Conclusion}

The consumption of chestnuts could be an important contribution to the intake of antioxidants such as ascorbic acid and phenolic compounds. A method for the HPLC determination allows the identification and quantification in 14 min of eight organic acids: oxalic, glutamic, tartaric, pyruvic, malic, citric, fumaric and cis-aconitic acids. The concentrations of organic acids in chestnut arranged according to the following sequence: Ascorbic acid $>$ citric acid $>$ malic acid $>$ glutamic acid $>$ tartaric acid $>$ fumaric acid $>$ cis-aconitic acid $>$ pyruvic acid. A correlation between glucose and fructose was established suggesting a common origin of both sugars. Some correlations between organic acids were observed emphasizing the correlation malic and fumaric acids.

\section{Acknowledgements}

This paper is a part of the project "Germobanco Agrícola de la Macaronesia" within Interreg III-B European program. This work was financed by the Project $(\mathrm{R}+\mathrm{D})$ Reference PI042004/030 (2005) of the Gobierno de Canarias, Spain. We also wish to thank the technicians from the Excmo. Cabildo Insular de Tenerife (Insular Government) sampled and authenticated the chestnuts. We also acknowledge the help of Patrick Dennis for revising the English in this paper.

\section{REFERENCES}

[1] F. B. Hu, M. J. Stampfer, J. E. Manson, E. B. Rimm, G. A. Colditz, B. A. Rosner, F. E. Speizer, C. H. Hennekens and W. C. Willett, "Frequent Nut Consumption and Risk of Coronary Heart Disease in Women: Prospective Cohort Study," British Medical Journal, Vol. 317, 1998, pp. 1341-1345. doi:10.1136/bmj.317.7169.1341

[2] U. Künsch, H. Schärer, B. Patrian, J. Hurter, M. Conedera, A. Sassella, J. Jermini and G. Jelmini, "Quality Assessment of Chestnut Fruits," Acta Horticulturae, Vol. 494, 1999, pp. 119-127.

[3] U. Künsch, H. Schärer, B. Patrian, E. Höhn, M. Conedera, A. Sassella, M. Jermini and G. Jelmini, "Effects of Roasting on Chemical Composition and Quality of Different Chestnut (Castanea sativa Mill.) Varieties," Journal of the Science of Food and Agriculture, Vol. 81, 2001, pp. 1106-1112. doi:10.1002/jsfa.916

[4] S. D. Senter, J. A. Payne, G. Miller and S. L. Anagnostakism, "Comparison of Total Lipids, Fatty Acids, Sugars and Nonvolatile Organic Acids in Nuts from Castanea Species," Journal of the Science of Food and Agriculture, Vol. 65, 1994, pp. 223-227. doi:10.1002/jsfa.2740650216

[5] J. G. Vaughan and C. A. Geissler, "The New Oxford Book of Food Plants," Oxford University Press, New York, 1997.

[6] B. M. Silva, P. B. Andrade, G. C. Mendes, R. M. Seabra and M. A. Ferreira, "Study of the Organic Acids Composition of Quince (Cydonia oblonga Miller) Fruit and Jam," Journal of Agricultural and Food Chemistry, Vol. 50, No. 8, 2002, pp. 2313-2317. doi:10.1021/jf011286+

[7] P. Valentão, G. Lopes, M. Valente, P. Barbosa, P. B. 
Andrade, B. M. Silva, P. Baptista and R. M. Seabra, "Quantitation of Nine Organic Acids in Wild Mushrooms," Journal of Agricultural and Food Chemistry, Vol. 53, No. 9, 2005, pp. 3626-3630. doi:10.1021/jf040465z

[8] B. M. Silva, P. B. Andrade, A. C. Gonçalves, R. M. Seabra, M. B. Oliveira and M. A. Ferreira, "Influence of Jam Processing upon the Contents of Phenolics, Organic Acids and Free Amino Acids in Quince Fruit (Cydonia oblonga Miller)," European Food Research and Technology, Vol. 218, 2004, pp. 385-389. doi:10.1007/s00217-003-0845-6

[9] P. Valentão, P. B. Andrade, J. Rangel, B. Ribeiro, B. M. Silva, P. Baptista and R. M. Seabra, "Effect of the Conservation Procedure on the Contents of Phenolic Compounds and Organic Acids in Chanterelle (Cantharellus cibarius) Mushroom," Journal of Agricultural and Food Chemistry, Vol. 53, No. 12, 2005, pp. 4925-4931. doi:10.1021/jf0580263

[10] B. M. Silva, P. B. Andrade, P. Valentão, F. Ferreres, R. M. Seabra and M. A. Ferreira, "Quince (Cydonia oblonga Miller) Fruit (Pulp, Peel, and Seed) and Jam: Antioxidant Activity," Journal of Agricultural and Food Chemistry, Vol. 52, No. 15, 2004, pp. 4705-4712. doi:10.1021/if040057v

[11] S. Pereira-Lorenzo, B. Díaz-Hernández, M. Ciordia-Ara, J. Ascasibar-Errasti, A. M. Ramos-Cabrer and F. Sal, "Spanish Chestnut Cultivars," HortScience, Vol. 36, No. 2, 2001, pp. 344-347.

[12] AOAC, "Official Methods of Analysis of AOAC International," Association Official of Analytical Chemists, Gaithersburg, 2006.

[13] T. S. Kujala, J. M. Loponen, K. D. Klika and K. Pihlaja, "Phenolic and Betacyanins in Red Beetroot (Beta vulgaris) Root: Distribution and Effect of Cold Storage on the Content of Total Phenolic and Three Individual Compounds," Journal of Agriculture and Food Chemistry, Vol. 48, 2000, pp. 5338-5342. doi:10.1021/jf000523q

[14] B. R. Galdón, C. T. Rodríguez, E. M. R. Rodríguez and C. D. Romero, "Fructans and Major Compounds in Onion Cultivars (Allium cepa)," Journal of Food Composition and Analysis, Vol. 22, No. 1, 2009, pp. 25-32. doi:10.1016/j.jfca.2008.07.007

[15] M. H. Suárez, E. M. R. Rodríguez and C. D. Romero, "Analysis of Organic Acid Content in Cultivars of Tomato Harvested in Tenerife," European Food Research and Technology, Vol. 226, 2008, pp. 423-435. doi:10.1007/s00217-006-0553-0

[16] L. M. P. González, M. H. Suárez, C. D. Romero and E. M. R. Rodríguez, "Composición Química de Cultivares Locales de Castañas de Tenerife: I. Composición Química y Contenido de Antioxidantes," Ciencia y Tecnología Alimentaria, Vol. 5, No. 3, 2006, pp. 195-205.

[17] M. C. B. M. de Vasconcelos, R. N. Bennett, E. A. S. Rosa and J. V. F. Cardoso, "Primary and Secondary Metabolite Composition of Kernels from Three Cultivars of Portuguese Chestnut (Castanea sativa Mill.) at Different Stages of Industrial Transformation," Journal of Agriculture and Food Chemistry, Vol. 55, No. 9, 2007, pp. 3508-3516. doi:10.1021/jf0629080
[18] J. C. M. Barreira, S. Casal, I. C. F. R. Ferreira, M. B. P. P. Oliveira and J. A. Pereira, "Nutritional, Fatty Acid and Triacylglycerol Profiles of Castanea sativa Mill. Cultivars: A Composition and Chemometric Approach," Journal of Agricultural and Food Chemistry, Vol. 57, 2009, pp. 2836-2842. doi:10.1021/jf803754u

[19] O. Borges, B. Gonçalves, J. L. S. de Carvalho, P. Correia and A. P. Silva, "Nutritional Quality of Chestnut (Castanea sativa Mill.) Cultivars from Portugal," Food Chemistry, Vol. 106, No. 3, 2008, pp. 976-984. doi:10.1016/j.foodchem.2007.07.011

[20] S. A. Vekiari, E. Panagou and C. Mallidis, "Compositional Analysis of Chestnuts in Mediterranean Countries," Advances Horticultural Science, Vol. 20, 2006, pp. 90-95.

[21] S. Pereira-Lorenzo, A. M. Ramos-Cabrer, M. B. DíazHernández, M. Ciordia-Ara and D. Ríos-Mesa, "Chemical Composition of Chestnut Cultivars from Spain," Scientia Horticulturae, Vol. 107, No. 3, 2006, pp. 306-314. doi:10.1016/j.scienta.2005.08.008

[22] J. De la M. Míguelez, M. M. Bernárdez and J. M. G. Queijerio, "Composition of Varieties of Chestnuts from Galicia (Spain),” Food Chemistry, Vol. 84, No. 3, 2004, pp. 401-404. doi:10.1016/S0308-8146(03)00249-8

[23] G. Attanasio, L. Cinquanta, D. Albanese and M. Di Matteo, "Effects of Drying Temperatures on Physico-Chemical Properties of Dried and Rehydrated Chestnuts (Castanea sativa)," Food Chemistry, Vol. 88, No. 4, 2004, pp. 583-590. doi:10.1016/j.foodchem.2004.01.071

[24] U. Ertürk, C. Mert and A. Soylu, "Chemical Composition of Fruits of Some Important Chestnut Cultivars," Brazilian Archives of Biology and Technology, Vol. 44, 2006, pp. 69-78.

[25] L. Neri, G. Dimitri and G. Sacchetti, "Chemical Composition and Antioxidant Activity of Cured Chestnuts from Three Sweet Chestnut (Castanea sativa Mill.) Ecotypes from Italy," Journal of Food Composition and Analysis, Vol. 23, No. 1, 2010, pp. 23-29. doi:10.1016/j.jfca.2009.03.002

[26] E. M. D. Medina, E. M. R. Rodríguez and C. Díaz Romero, "Chemical Characterization of Opuntia dillenii and Opuntia ficus indica Fruits," Food Chemistry, Vol. 103, No. 1, 2007, pp. 38-45.

doi:10.1016/j.foodchem.2006.06.064

[27] S. M. Krebs-Smith, D. A. Cook, A. F. Subar, L. Cleveland and J. Friday, "US Adults' Fruit and Vegetable Intakes, 1989 to 1991: A Revised Baseline for the Healthy People 2000 Objective," American Journal of Public Health, Vol. 85, No. 12, 1995, pp. 1623-1629. doi:10.2105/AJPH.85.12.1623

[28] J. S. Xu, T. L. Zheng, S. Meguro and S. Kawachi, "Purification and Characterization of Polyphenol Oxidase from Henryi Chestnuts (Castanea henryi)," Journal of Wood Science, Vol. 50, No. 3, 2004, pp. 260-265. doi:10.1007/s10086-003-0554-6

[29] S. A. Vekiari, E. Z. Panagou and C. Mallidis, "The Effects of Cold Storage on the Quality of Peeled, Raw or Heat-Treated Greek Chestnuts Packed under Vacuum," Journal of Horticultural Science and Biotechnology, Vol. 82, 2007, pp. 967-973. 
[30] E. Bellini, E. Giordani, C. Marinelli and B. Perucca, "Marrone del Mugello. PGI Chestnut Nutritional and Organoleptic Quality," Acta Horticulturae, Vol. 693, 2005, pp. 97-101.

[31] E. Bellini, E. Giordani, C. Marinelli, M. Migliorini and L. Funghini, "Marrone del Mugello PGI: Nutritional and Organoleptic Quality of European Chestnut (Castanea sativa Mill.) Flour," Acta Horticulturae, Vol. 815, 2009, pp. 117-124.

[32] J. C. M. Barreira, I. C. F. R. Ferreira, M. B. P. P. Oliveira and J. A. Pereira, "Antioxidant Activities of the Extracts from Chestnuts Flower, Leaf, Skins and Fruit," Food Chemistry, Vol. 107, No. 3, 2008, pp. 1106-1113. doi:10.1016/i.foodchem.2007.09.030

[33] B. Ribeiro, J. Rangel, P. Valentão, P. B. Andrade, J. A. Pereira, H. Bölke and R. M. Seabra, "Organic Acids in Two Portuguese Chestnut (Castanea sativa Miller) Varieties," Food Chemistry, Vol. 100, No. 2, 2007, pp. 504508. doi:10.1016/i.foodchem.2005.09.073

[34] J. B. Harborne, H. Baxter and G. P. Moss, "Phyto-Chemical Dictionary: A Handbook of Bioactive Compounds from Plants," 2nd Edition, Taylor \& Francis, London, 1999.

[35] H. Iwase, "Use of an Amino Acid in the Mobile Phase for the Determination of Ascorbic Acid in Food by HighPerformance Liquid Chromatography with Electrochemical Detection," Journal of Chromatography A, Vol. 881, No. 1, 2000, pp. 317-326.
doi:10.1016/S0021-9673(00)00199-0

[36] H. Iwase and I. Ono, "Determination of Ascorbic Acid in Food by Column Liquid Chromatography with Electrochemical Detection Using Eluent for Pre-Run Sample Stabilization," Journal of Chromatography A, Vol. 806, No. 2, 1998, pp. 361-364. doi:10.1016/S0021-9673(98)00062-4

[37] F. Chinnici, U. Spinabelli, C. Riponi and A. Amati, "Optimization of the Determination of Organic Acids and Sugars in Fruit Juices by Ion-Exclusion Liquid Chromatography," Journal of Food Composition and Analysis, Vol. 18, No. 2-3, 2005, pp. 121-130. doi:10.1016/j.jfca.2004.01.005

[38] F. J. Mataix, "Recomendaciones Nutricionales y Alimentarias Para la Población. Necesidad y Limitaciones," Alimentación, Nutrición y Salud, Vol. 3, 1996, pp. 51-57.

[39] E. M. Peña-Méndez, M. Hernández-Suárez, C. Díaz-Romero and E. M. Rodríguez-Rodríguez, "Characterization of Various Chestnut Cultivars by Means of Chemometrics Approach," Food Chemistry, Vol. 107, No. 1, 2008, pp. 537-544. doi:10.1016/j.foodchem.2007.08.024

[40] S. Mitjavila, "Sustancias Naturales Nocivas en Los Alimentos," Toxicología y Seguridad de los Alimentos, Omega, Barcelona, 1990.

[41] B. Li, D. Geiger and W. Shieh, "Evidence for Circadian Regulation of Starch and Sucrose Synthesis in Sugar Beet Leaves," Plant Physiology, Vol. 99, No. 4, 1992, pp. 1393-1399. doi:10.1104/pp.99.4.1393 